\title{
Incidence of intraepithelial fallopian tube neoplasias in mexican women over 40 years of age that underwent elective hysterectomy
}

\author{
Antonio Gabriel Briseño Campos ${ }^{1}$, Antonio Cruz Rodríguez ${ }^{2 *}$, Martha Olivia García Perales ${ }^{3}$, \\ Francisco Javier Serna Vela ${ }^{4}$, Diana Gabriela Camarillo Elizalde ${ }^{5}$ and María del Consuelo Robles Martínez ${ }^{6}$
}

\begin{abstract}
Aims: The incidence of intraepithelial neoplasia in the fallopian tubes of women over 40 years of age who had undergone elective hysterectomy was assessed at the Aguascalientes Women's Hospital.

Methods: An observational, prospective, descriptive study was carried out at the Aguascalientes Women's Hospital on female patients over 40 years of age who underwent elective hysterectomy between July and October 2017. In these 4 months, 85 patients underwent elective hysterectomy.

Results: In this study, 85 patients who received a hysterectomy for non-oncological reasons were analyzed. Salpinx alterations compatible with intraepithelial neoplasia in the Fallopian tubes were found in $2.4 \%$ of the patients studied.

Conclusions: The incidence of intraepithelial neoplasia in the fallopian tubes of high-risk patients at the Aguascalientes Women's Hospital is $2.4 \%$. Prophylactic salpingectomy is a simple procedure and has the potential to decrease the risk of high-grade ovarian cancer. In premenopausal patients, total abdominal hysterectomy with bilateral salpingectomy should be the procedure most often performed.
\end{abstract}

Keywords: Malignant; ovarian tumor, Hysterectomy, Salpinge, Prophylactic salpingectomy

\section{Background}

Serous carcinomas are the most common histological subtype of ovarian epithelial cancers and in recent years, a very close relationship has been found between peritoneal and fallopian tube carcinoma based on their histological similarities and clinical behavior. As a result, it has been proposed that these carcinomas (ovarian, peritoneal and fallopian tube) all develop from the fallopian tubes [1]. Indeed, studies of the pathogenesis and heterogeneity of epithelial ovarian cancer concluded that most ovarian cancers originate from the secretory cells of the fallopian tube, although what triggers this neoplastic transformation remains unclear [2-6]. Indeed, the precursors of high-grade serous cancer were

\footnotetext{
*Correspondence: cruz_cirujano@hortmail.com

${ }^{2}$ Gynecological Oncology Department, Aguascalientes Women's Hospital,

Siglo XXI \# 109; Morelos, 20298 Aguascalientes, Mexico

Full list of author information is available at the end of the article
}

identified in the fallopian tubes, which is now defined as Serous Tubal Intraepithelial Cancer (STIC) [7]. This evidence that high-grade serous carcinomas actually arise from the fallopian tube suggests that the incidence of fallopian tube carcinoma may be higher than previously thought.

In this study we set out to study the incidence of STICs in a population of women older than 40 years of age that underwent elective hysterectomy in a single center in Mexico. The results emphasize the benefits to be obtained by performing prophylactic salpingectomy in this population of women in order to reduce the risk of carcinoma.

Ovarian cancer is the second most common gynecological cancer and it is the leading cause of death from gynecological cancer in the United States [8]. Fallopian tube carcinoma represents $0.2 \%$ of the cancers in women in the USA [9], while in Mexico, the National 
Cancer Institute registers more than 2500 new cases of ovarian cancer each year, ranking third in the number of gynecological cancers in our country. Most cases are diagnosed in women between 40 and 59 years of age [10], and while around $95 \%$ of malignant ovarian tumors are of epithelial origin,the rest originate from other types of ovarian cells, germ or stromal cells.

There are 2 hypotheses regarding the development of epithelial ovarian cancer:

- Incessant ovulation: trauma in the epithelium of the ovary provokes transformation into malignant cells and indeed, epithelial ovarian cancer is less common in women who undergo periodic suppression of ovulation (contraceptives, pregnancy, lactation) [11].

- Exposure to gonadotropins: persistent exposure of the ovary to gonadotropins and elevated estradiol levels may have a carcinogenic effect [12].

In women under 50 years of age, the incidence of ovarian cancer increases by $2 \%$ each year, while its incidence increases by $11 \%$ after 50 years of age [13]. The women at highest risk are those within the period of fertility, those who experience menarche before the age of 12 or menopause after the age of 52 [14], the use of hormone replacement therapy [15], nulliparity [16], endometriosis (which increases the risk for clear cell cancer, low grade endometrioid cancer and cancer of the serous type) [17], polycystic ovary [18], and the use of copper IUDs [19]. Smoking increases the risk of mucinous ovarian cancer and asbestos exposure augments the risk of epithelial ovariancancer [13]. The mutation of some genes has also been associated with an increased risk of epithelial ovarian cancer, such as BRCA1 and BRCA2, BRIP1, RAD51C and RAD51D [14, 15]. Conversely, women who use oral contraceptives or levonorgestrel IUDs and women with multiparity have a lower risk of developing epithelial ovarian cancer [14, 20-22]. In fact, term pregnancies reduce the risk of epithelial ovarian cancer by $8 \%$ for each pregnancy [23] and multiple pregnancies [24], as well as pregnancies under 35 years of age, are also protective factors $[18,25]$. Ovulation inducers do not increase the risk of this type of tumor [26].

In 1990, risk reduction surgery for epithelial ovarian cancer began to be implemented in patients with mutations in BRCA1 and BRCA2. At this time hidden neoplasms began to be identified in the fallopian tubes, even in association with microscopic invasion in high-grade serous carcinomas and high-grade intraepithelial neoplasia, suggesting that the fallopian tube could be the origin of high-grade non-uterine pelvic serous carcinomas. Bilateral salpingectomy-oophorectomy reduces mortality in patients carrying mutations inBRCA1 and BRCA2, individuals at a high risk of developing high-grade serous carcinomas. Moreover, bilateral salpingectomy is recommended in patients with no risk factors for epithelial ovarian cancer when a definitive method of family planning is required and in patients undergoing hysterectomy, although the ovaries are preserved in these procedures. The consequences of salpingectomy have been analyzed in all women and in high-risk groups, focusing on morbidity, ovarian function and clinical application [27]. Opportunistic salpingectomy is performed to reduce the risk of epithelial ovarian cancer, yet some of these women may develop peritoneal carcinoma. Unilateral salpingectomy-oophorectomy, hysterectomy without oophorectomy and tubal ligation all reduce the risk of epithelial ovarian cancer, more so when considering non-serous carcinomas and in individuals under 35 years of age) [28-30].

\section{Materials and methods}

An observational, descriptive, prospective study was carried out over a period of 4 months. Patients older than 40 years of age with a preoperative diagnosis of a benign pathology and that were recommended a surgical protocol for abdominal hysterectomy were included in this study. Patients under 40 years of age and not recommended a full surgical protocol were excluded from the study and a patient that refused to participate in the study was eliminated from the cohort.

The dependent variable assessed was STIC development and the independent variables were age, parity, menarche, pregnancy, null parity, family history of ovarian cancer, smoking and endometriosis. The type of sample is non-probabilistic and the sample size was the total of the 85 patients included on the study.

The phatologic samples were stained with hematoxylin/ eosin; these were prepared in paraffin with $2 \mathrm{~mm}$ sections.

The study was carried out in accordance with the guidelines for General Health Law regarding research and specifically, with that regulating descriptive studies carried out on humans. The study also complies with the rights of patients and respects their rights to confidentiality by adhering to the Helsinki and Belmont declarations regarding human research.

\section{Results}

The mean age of the cohort was 48.45 years ( \pm 7.51 : Fig. 1 ).

Gynecological and obstetric history are shown in Table 1, but they show no relevant data.

The main indication for undergoing hysterectomy among the subjects included in the study was uterine myomatosis, with a frequency of 54 cases $(63.5 \%)$, consistent with the existing literature (Table 2), then pelvic organ prolapse was the surgery indication $(9.4 \%)$. Postmenopausal bleeding, uterine bleeding refractory to 


\section{Age (patients included)}

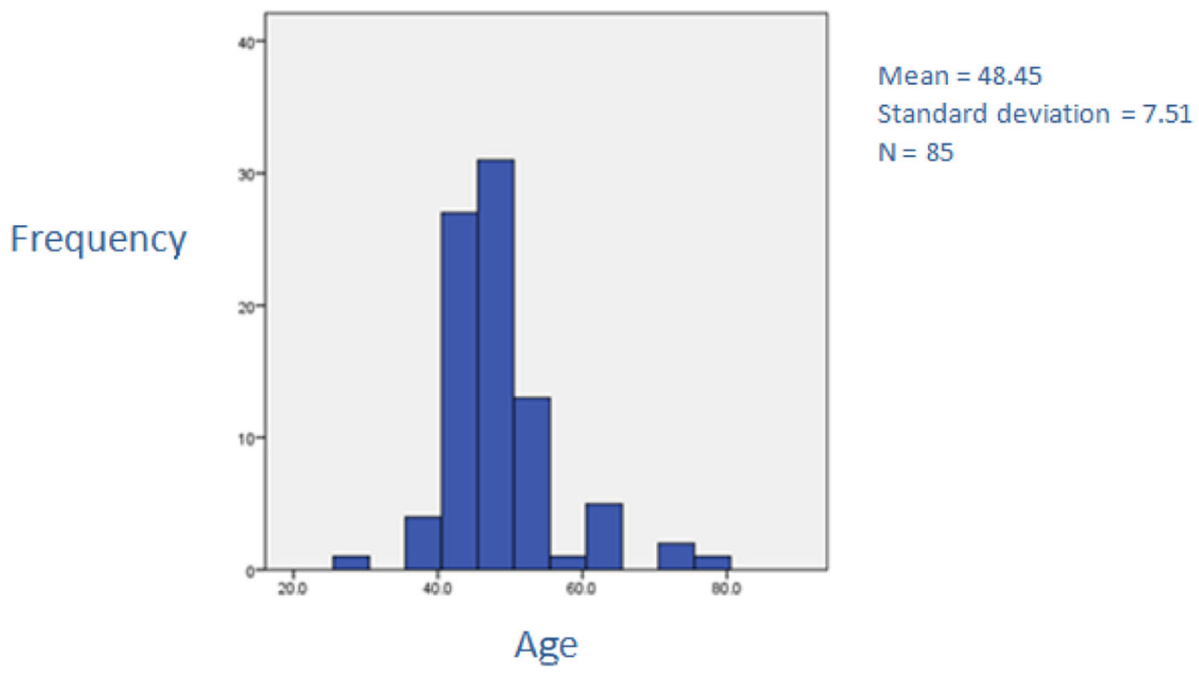

Fig. 1 The age of the patients that underwent hysterectomy and opportunistic salpingectomy (range 40-76 years of age)

treatment and mature cyst teratoma showed low frequency $(1.2 \%)$.

Total hysterectomy with bilateral salpingo-oophorectomy was the procedure performed most often, in $50.7 \%$ of the patients including abdominal and vaginal surgery $\left(\right.$ Table $3^{\mathrm{a}}$ ). The age group of patients studied corresponds to women at perimenopause and menopause. It is striking that right oophorectomy was performed more frequently.

We failed to find any type of pathological alterations in $81.2 \%$ of the patients, whereas the incidence of patients who presented with serous carcinoma of the ovary was $4.8 \%$ and the preoperative diagnosis was that of an adnexal tumor that was subjected to further study. One case of a perivascular tumor of epithelioid cells in the salpinge was detected, while two patients had STIC, corresponding to $2.4 \%$ of the patients who entered the study (Figs. 2). The patients in which STIC was detected were 44 and 55 years of age, both with a pre-surgical diagnosis of uterine myomatosis. The patients with STIC had a history of a family member with breast cancer, whereas none of the patients had a family history of ovarian cancer.

\section{Discussion}

Since 1990, the rise of risk-reduction surgery in patients carrying mutations in BRCA led to the detection of hidden neoplasms in the Fallopian tubes of patients over 40 years of age. Indeed, high-grade epithelial ovarian cancer is associated with precursor lesions in the fallopian tube epithelium [3-7]. Here, we assessed the incidence of

Table 1 Gynecological and Obstetric Background of the patients undergoing opportunistic salpingectomy

\begin{tabular}{|c|c|c|c|c|c|c|c|}
\hline \multicolumn{8}{|c|}{ Gynecological -Obstetric History Of The Patients Studied } \\
\hline & & Menarche & Gestations & Births & Ectopic Pregnancies & Abortions & Cesareans \\
\hline \multirow[t]{2}{*}{ No. } & Valid & 85 & 85 & 85 & 85 & 85 & 85 \\
\hline & Lost & 0 & 0 & 0 & 0 & 0 & 0 \\
\hline \multicolumn{2}{|c|}{ Mean } & 11.7 & 3.7 & 2.7 & 0.012 & 0.4 & 0.62 \\
\hline \multicolumn{2}{|c|}{ Median } & 12.0 & 3.0 & 2.0 & 0 & 0 & 0 \\
\hline \multicolumn{2}{|c|}{ Mode } & 11.0 & 3.0 & 2.0 & 0 & 0 & 0 \\
\hline \multicolumn{2}{|c|}{ Standard Deviation } & 1.5 & 2.6 & 2.5 & 0.1 & 0.7 & 1.0 \\
\hline \multicolumn{2}{|c|}{ Variance } & 2.2 & 6.9 & 6.6 & 0.01 & 0.5 & 1.1 \\
\hline \multicolumn{2}{|c|}{ Rank } & 6.0 & 13.0 & 13.0 & 1.0 & 4.0 & 4.0 \\
\hline \multicolumn{2}{|c|}{ Minimum } & 9.0 & 0 & 0 & 0 & 0 & 0 \\
\hline \multicolumn{2}{|c|}{ Maximum } & 15.0 & 13.0 & 13.0 & 1.0 & 4.0 & 4.0 \\
\hline
\end{tabular}


Table 2 Pre-surgical diagnosis

\begin{tabular}{|c|c|c|c|c|}
\hline \multicolumn{5}{|l|}{ Hysterectomy Indications } \\
\hline & Frequency & Percentage & Valid percentage & Accumulated percentage \\
\hline Adenomyosis & 7 & 8.2 & 8.2 & 8.2 \\
\hline Endometrial hyperplasia & 4 & 4.7 & 4.7 & 12.9 \\
\hline Uterine myomatosis & 54 & 63.5 & 63.5 & 76.5 \\
\hline Endometrial polyps & 3 & 3.5 & 3.5 & 80.0 \\
\hline Pelvic organ prolapse & 8 & 9.4 & 9.4 & 89.4 \\
\hline Postmenopausal bleeding & 1 & 1.2 & 1.2 & 90.6 \\
\hline Uterine bleeding refractory to treatment & 1 & 1.2 & 1.2 & 91.8 \\
\hline Mature cyst teratoma & 1 & 1.2 & 1.2 & 92.9 \\
\hline Anexial tumor & 5 & 6.0 & 6.0 & 100.0 \\
\hline TOTAL & 85 & 100.0 & 100.0 & \\
\hline
\end{tabular}

STICs in a population of Mexican women of at least 40 years of age that underwent elective hysterectomy at our clinical center. The average age of the patients studied here was 48 years, similar to those in a study conducted in Japan in 2016 [6], and the individuals in which STIC was detected here were 44 and 55 years old. However, we do not know the incidence of STIC in patients under 40 years of age, largely because it is less common to perform a hysterectomy in patients of that age.

The main indication for performing a hysterectomy in our study was uterine myomatosis, which is consistent with the existing literature. The STIC positive patients experienced menarche at 11 and 10 years of age, and while one of the patients had 2 pregnancies during her reproductive life (one delivery and one abortion), the other patient had a single cesarean section. Endometriosis was not found in patients positive for STIC and a BRCA test was not carried out due to the lack of financial resources. However, it is notable that the incidence of STIC in the BRCA positive population is $30-40 \%$ in the literature [6].
Total hysterectomy with bilateral salpingo-oophorectomy was the procedure most often performed in this cohort (50.7\% of cases), with bilateral salpingectomy also carried out frequently (44.8\% of cases). The age group of the individuals studied corresponds to a perimenopausal and menopausal population, and accordingly, the STIC-positive patients underwent total abdominal hysterectomy with bilateral salpingectomy. In low risk patients there is no preventive measure to reduce the risk of ovarian cancer, yet it would appear that prophylactic salpingectomies could reduce the risk of developing high-grade ovarian cancer [3, 27]. Nevertheless, the incidence of STIC in low-risk women is an issue that has been little studied and while an incidence of STIC of $3.2 \%$ was reported in low risk women in Japan in 2016 [6], no such data is available in Mexico. From our data it appears that we could reduce the risk of high-grade epithelial ovarian cancer in 2 out of every 100 patients that undergo opportunist salpingectomy. If we also take into account the study conducted previously in Japan in 2016 [6], a total of 208 patients have been studied of whom 6 were diagnosed with STIC, an incidence of $2.88 \%$.

Table 3 Surgical procedure performed in the population undergoing opportunistic salpingectomy

\begin{tabular}{|c|c|c|c|c|}
\hline \multicolumn{5}{|l|}{ Surgical Procedure Performed } \\
\hline & Frequency & Percentage & $\begin{array}{l}\text { Valid } \\
\text { percentage }\end{array}$ & $\begin{array}{l}\text { Accumulated } \\
\text { percentage }\end{array}$ \\
\hline $\begin{array}{l}\text { Abdominal subtotal hysterectomy + bilateral salpingectomy + right } \\
\text { oophorectomy }\end{array}$ & 1 & 1.2 & 1.2 & 1.2 \\
\hline Abdominal total hysterectomy + bilateral salpingectomy & 13 & 15.3 & 15.3 & 16.5 \\
\hline Abdominal total hysterectomy + bilateral salpingectomy + right oophorectomy & 17 & 20.0 & 20.0 & 36.5 \\
\hline Abdominal total hysterectomy + bilateral salpingectomy + left oophorectomy & 6 & 7.1 & 7.1 & 43.6 \\
\hline Abdominal total hysterectomy + bilateral salpingo-oophorectomy & 37 & $43.6^{\mathrm{a}}$ & 43.6 & 87.2 \\
\hline Abdominal total hysterectomy + right salpingo-oophorectomy & 3 & 3.5 & 3.5 & 90.7 \\
\hline Vaginal hysterectomy + bilateral salpingectomy + left oophorectomy & 1 & 1.2 & 1.2 & 92.9 \\
\hline Vaginal hysterectomy + bilateral salpingo-oophorectomy & 6 & $7.1^{\mathrm{a}}$ & 7.1 & 100.0 \\
\hline Total & 85 & 100.0 & 100.0 & \\
\hline
\end{tabular}




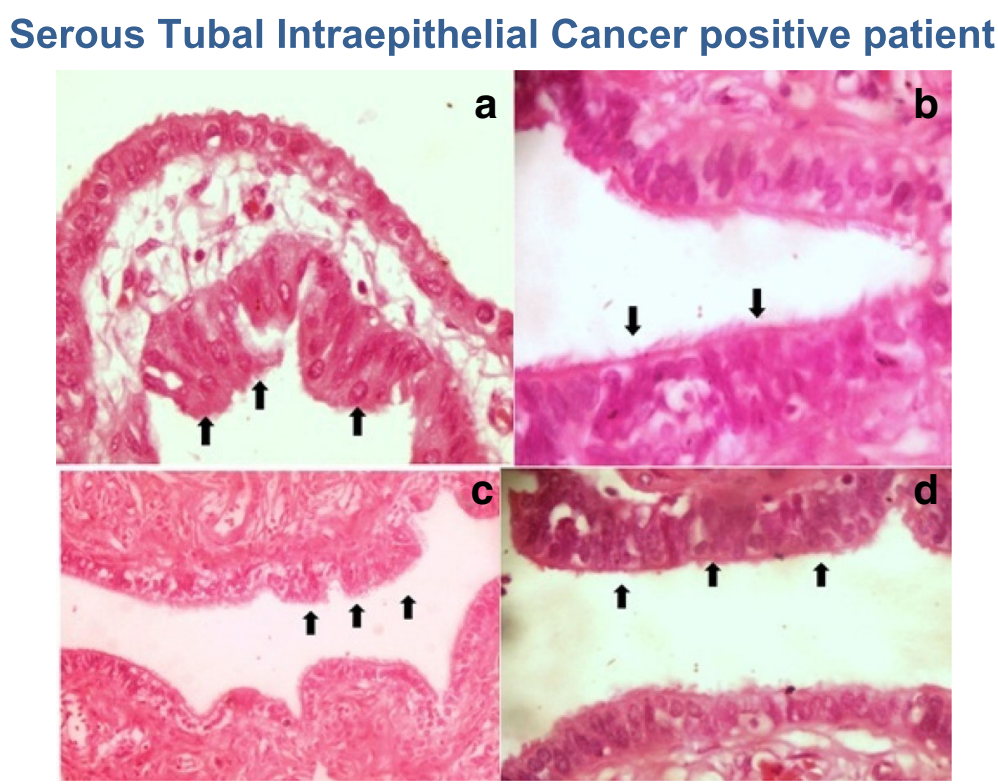

Fig. 2 a-b.STIC positive patient S-17644. c-d.STIC positive patient S-17754. The black arrows indicate nuclear enlargement, loss of polarity and atypia

In our institution 1814 bilateral tubal occlusions are performed in the population of childbearing age. The lack of applicability as a multicenter study to increase the sample is considered a limitation of the study. This represents an opportunity to perform opportunistic salpingectomy and thereby reduce the risk of high-grade ovarian cancer in 240 patients per 100,000.

\section{Conclusion}

The incidence of STIC in a low risk population in Mexico is $2.4 \%$. Prophylactic salpingectomy should be performed in all patients undergoing hysterectomy as it reduces the risk of developing high-grade ovarian cancer. The main indication for hysterectomy in our institution was uterine myomatosis, and the procedure most commonly performed in perimenopausal and menopausal patients was total abdominal hysterectomy with bilateral salpingo-oophorectomy. This should also be the most common procedure offered to premenopausal patients.

\section{Perspectives}

In this study, we set out to determine the incidence of STIC in a population of low risk patients. However, it would be prudent to analyze alterations toTP53 in such low risk populations in order to study alterations to the fallopian tubes. We believe that this study may be useful to improve the gynecological attention given to women and to promote the use of prophylactic salpingectomy in women of this age, with the aim of reducing the occurrence of high grade ovarian cancer in this population.

\section{Acknowledgements}

Acknowledgements to Dr. Mark Sefton from BiomedRed who provided professionalwrititng services.

\section{Funding}

No economic funds were required.

\section{Availability of data and materials}

The datasets used and/or analysed during the current study are available from the corresponding author on reasonable request.

\section{Authors' contributions}

1 BC made acquisition of data, analysis and interpretation of data. 2CR made substancial contributions to conception and design. 3GP made substantial contributions by analysis of pathological samples. 4SV made substantial contributions to analysis and interpretation of data. 5 CE agreed to be accountable for all aspects of the work in ensuring that questions related to the accuracy or integrity of any part of the work are appropriately investigated and resolved. 6RM been involved in drafting the manuscript and gived final approval of theversion to be published. All authors read and approved the final manuscript.

\section{Ethics approval and consent to participate}

The state research committee awarded the registration number (ISSEA-002/ 18) to.

the investigation. The patients signed informed consent for the surgical procedure.

\section{Consent for publication}

Not applicable. This manuscript does not contain data from any individual person.

\section{Competing interests}

The authors declare that they have no competing interests.

\section{Publisher's Note}

Springer Nature remains neutral with regard to jurisdictional claims in published maps and institutional affiliations. 


\section{Author details}

Gynecology and Obstetrics, Aguascalientes Women's Hospital, Aguascalientes, Mexico. ${ }^{2}$ Gynecological Oncology Department, Aguascalientes Women's Hospital, Siglo XXI \# 109; Morelos, 20298 Aguascalientes, Mexico. ${ }^{3}$ Pathology and Cytopathology Laboratory, Aguascalientes, Mexico. ${ }^{4}$ Institute of Health Services of the State of Aguascalientes, Aguascalientes, Mexico. ${ }^{5}$ Public Health Department of the Health Science Center at the Autonomous University of Aguascalientes, Aguascalientes, Mexico. ${ }^{6}$ Gynecology and Obstetrics Department, Aguascalientes Women's Hospital, Aguascalientes, Mexico.

Received: 16 November 2018 Accepted: 18 April 2019

Published online: 10 June 2019

\section{References}

1. Lacey JV, Sherman ME, Robboy SL, Mutter GL, Prat J, et al. Ovarian neoplasia. In: Robboy's pathology of the female reproductive tract. 2nd ed. Oxford: Churchill Livingstone Elsevier; 2009. p. 601.

2. Kroeger PT Jr, Dreapkin R. Pathogenesis and heterogeneity of ovarian cancer. Curr Opin Obstet Gynecol. 2017 Feb;29(1):26-34. https://doi.org/10. 1097/GCO.0000000000000340.

3. George SH, García R, Slomovitz BM. Ovarian Cancer: the fallopian tube as the site of origin and opportunities for prevention. Front Oncol. 2016;6:108. https://doi.org/10.3389/fonc.2016.00108 eCollection 2016.

4. The fallopian tube as the origin of high grade serous ovarian cancer: review of a paradigm shift. J Obstet Gynaecol Can. 2014 Feb;36(2):133-140. doi: https://doi.org/10.1016/S1701-2163(15) 30659-9.

5. Zweemer RP, van Diest PJ, Verheijen RH, et al. Molecular evidence linking primary cancer of the fallopian tube to BRCA1 germline mutations. GynecolOncol. 2000;76:45-50

6. Nishida N, Murakami F, Higaki K. Detection of serous precursor lesions in resected fallopian tubes from patients with benign diseases and a relatively low risk for ovarian cáncer. Pathol Int. 2016;66:337-42.

7. Singh, Naveena MD; Manchanda Ranjit, MD, Persistence of fimbrial tissue on the ovarian surface after salpingectomy. American Journal of Obstetrics \& Gynecology 2017 425.e1-e16.

8. http://seer.cancer.gov/statfacts/html/ovary.html

9. Stewart SL, Wike JM, Foster SL, Michaud F. The incidence of primary fallopian tube cancer in the United States. GynecolOncol. 2007;107:392.

10. (c) 2017 Programa de Cáncer de Ovario, INCAN.

11. Salehi F, Dunfield L, Phillips KP, et al. Risk factors for ovarian cancer: an overview with emphasis on hormonal factors. J Toxicol Environ Health B Crit Rev. 2008;11:301.

12. MA RBA, Hecht JL, Tworoger SS. Risk factors for epithelial ovarian cancer by histologic subtype. Am J Epidemiol. 2010;171:45.

13. Tsilidis KK, Allen NE, Key TJ, et al. Oral contraceptive use and reproductive factors and risk of ovarian cancer in the European prospective investigation into Cancer and nutrition. Br J Cancer. 2011;105:1436.

14. Zhou B, Sun Q, Cong R, et al. Hormone replacement therapy and ovarian cancer risk: a meta-analysis. GynecolOncol. 2008;108:641.

15. Stewart LM, Holman CD, Aboagye-Sarfo P, et al. In vitro fertilization, endometriosis, nulliparity and ovarian cancer risk. GynecolOncol. 2013;128: 260 .

16. Pearce $\mathrm{CL}$, Templeman $\mathrm{C}$, Rossing MA, et al. Association between endometriosis and risk of histological subtypes of ovarian cancer: a pooled analysis of case-control studies. Lancet Oncol. 2012;13:385.

17. Chittenden BG, Fullerton G, Maheshwari A, Bhattacharya S. Polycystic ovary syndrome and the risk of gynaecological cancer: a systematic review. Reprod BioMed Online. 2009;19:398.

18. Tworoger SS, Fairfield KM, Colditz GA, et al. Association of oral contraceptive use, other contraceptive methods, and infertility with ovarian cancer risk. Am J Epidemiol. 2007;166:894.

19. Song H, Dicks E, Ramus SJ, et al. Contribution of germline mutations in the RAD51B, RAD51C, and RAD51D genes to ovarian Cancer in the population. J ClinOncol. 2015:33:2901.

20. Sueblinvong T, Carney ME. Current understanding of risk factors for ovarian cancer. CurrTreat Options Oncol. 2009;10:67.

21. Soini T, Hurskainen R, Grénman S, et al. Cancer risk in women using the levonorgestrel-releasing intrauterine system in Finland. ObstetGynecol. 2014; 124:292.
22. Whiteman DC, Siskind V, Purdie DM, Green AC. Timing of pregnancy and the risk of epithelial ovarian cancer. Cancer Epidemiol Biomark Prev. 2003; $12: 42$

23. Whiteman DC, Murphy MF, Cook LS, et al. Multiple births and risk of epithelial ovarian cancer. J Natl Cancer Inst. 2000;92:1172.

24. Myung SK, Ju W, Choi HJ, et al. Soy intake and risk of endocrine-related gynaecological cancer: a meta-analysis. BJOG. 2009;116:1697.

25. Ness RB, Cramer DW, Goodman MT, et al. Infertility, fertility drugs, and ovarian cancer: a pooled analysis of case-control studies. Am J Epidemiol. 2002;155:217.

26. Yin L, Grandi N, Raum E, et al. Meta-analysis: circulating vitamin D and ovarian cancer risk. GynecolOncol. 2011;121:369.

27. Kara C., Long Roche MD, Nadeem R Abu-Rustum MD, Mlica Nourmoussavi MD., Zivanovic, O. MD. Risk-reducing salpingectomy: Let us be opportunistic. Cancer. May 15. Volume 123, Issue 10 Pages: 1675-1876, 2017 https://doi.org/10.1002/cncr.30528 Epub 2017 Mar 23.

28. Rice MS, Hankinson SE, Tworoger SS. Tubal ligation, hysterectomy, unilateral oophorectomy, and risk of ovarian cancer in the nurses. Health Studies FertilSteril. 2014;102:192.

29. Whittemore AS, Harris R, Itnyre J. Characteristics relating to ovarian cancer risk: collaborative analysis of 12 US case-control studies. II. Invasive epithelial ovarian cancers in white women. Collaborative ovarian Cancer group. Am J Epidemiol. 1992;136:1184.

30. Cibula D, Widschwendter M, Májek O, Dusek L. Tubal ligation and the risk of ovarian cancer: review and meta-analysis. HumReprodUpdate. 2011;17:55.
Ready to submit your research? Choose BMC and benefit from:

- fast, convenient online submission

- thorough peer review by experienced researchers in your field

- rapid publication on acceptance

- support for research data, including large and complex data types

- gold Open Access which fosters wider collaboration and increased citations

- maximum visibility for your research: over $100 \mathrm{M}$ website views per year

At BMC, research is always in progress.

Learn more biomedcentral.com/submissions 